\title{
Scientific Motivation of Young Scientists of Higher Educational Institutions (Engaged in Sociological Research)
}

\author{
Sofiya Malkaidarovna Duisenova
}

Al-Farabi Kazakh National University, 71 Al-Farabi ave, Almaty, Kazakhstan 050040

\section{Doi:10.5901/mjss.2015.v6n6s1p26}

\begin{abstract}
The purpose of the present article is to carry out conceptual and empirical analysis of the scientific motivation of young people of the Republic of Kazakhstan. In this article we showed the effectiveness of international experience, the effectiveness of science policy. The results of sociological research on the scientific motivation of students in higher educational institutions illustrate the desire of young bachelors and masters to improve their professional status, that is mostly connected with the desire to improve their social status in the society. However, this aspiration is complicated by the objective and subjective difficulties. The objective difficulties include the following: the lack of research funding in the country - both by the Ministry of Education and the Scientific Foundations (mainly "Samruk Kazyna"); the lack of national funds that finance scientific research; low wages for young scientists; insufficient number of grants for doctoral studies; inability to make a payment to pursue doctoral studies. Subjective difficulties include the following: the lack of sufficient scientific potential, the lack of young scientists, undeveloped grant rising and fond rising activities for students to have an opportunity to participate in competitions arranged by international scientific foundations and institutions, poor knowledge of a foreign language, which does not allow using various methodological foreign sources and foreign experience to the full extent. For the further formation of students' sustained motivation for research activities it is necessary to create certain conditions: to stimulate scientific activity of Kazakhstan and foreign scientific funds by means of special government programs (research projects, competitions) on support of the talented young scientists; to increase the prestige of university research; to solve social problems of young scientists.
\end{abstract}

Keywords: Scientific motivation, higher educational institutions, the Republic of Kazakhstan, young scientist.

\section{Introduction}

Science and innovation are key factors for promoting technological and social development, maintaining social harmony. In economically developed countries, there is an increase in expenditure on research and development and, consequently, an increase in the absolute number of personnel conducting research. As shown by international experience, high social status of representatives of the scientific communities is an indicator of socio-economic development of the state, the efficiency of its scientific and technological policy.

World experience has shown that in developed countries expenditure on research and development is constantly growing, in most such countries expenditure is reaching 2.5-3.7\% of GDP, while the state's share in these costs is 25$34 \%$ on average. These countries primarily include Israel (4.86\% of GDP), Finland (4.01\%), Sweden (3.75\%), Japan (3.42\%) and Korea (3.37\%). According to the estimates of international experts, sustainable development of the country requires that from 2 to $4 \%$ of GDP should be allocated to the science funding ("Science: difficult frontier in the struggle for survival", 2006). The threshold value of expenditure on research and development relative to GDP as a measure of economic security of the country is considered to be equal to $2 \%$. The share of expenditure on science, recommended by the International Academic Council, is equal to 1-1.5\% of GDP in developing countries. In the Republic of Kazakhstan in recent years, expenditure on research and development steadily increased in comparable amounts. "If in 2010, 20 billion tenge from the budget were allocated to science, by 2013 this figure reached 50 billion tenge, which is $0.18 \%$ of GDP. It is planned that by 2020 the funding of science will be $2 \%$ of GDP, in $2050-3 \%$ of GDP", - said the Minister at an expanded meeting on the development of science last Wednesday.

Young people engaged in education and science are one of the specific social and professional groups. On the one hand, the properties and characteristics of this group reflect the trends in youth development as a whole, on the other hand - the trends in the development of the professional community engaged in intellectual activities (scientific and pedagogical communities). At the same time, as noted by researchers, nowadays in higher education there are limitations of attracting young scientists caused by subjective and objective factors.

The process of professional formation of a group of young scientists in the framework of Kazakhstan and foreign 
practice has significant differences. The interest in the research activities in Kazakhstan universities is formed during undergraduate studies. Young scientists are usually engaged in the research process when pursuing doctoral studies. Professional formation of the scientist begins with public presentation of the thesis. In the course of doctoral studies the majority of young scientists conduct research activities and, at the same time, work as junior research scientists or teachers.

As already noted, modern society is going through a difficult phase of socio-economic reform, which requires scientific and technological breakthrough. The transition of science to a new level of development requires the creation of powerful personnel potential of young researches: energetic, active scientists with innovative thinking, competitive, striving for continuous improvement of their level of development, having professional mobility, a sense of responsibility, creativity. Nowadays a young scientist is not only an expert, having professional knowledge, skills and abilities, but also a person, whose scientific activity allows overcoming the stereotypes, to develop innovative ideas, as well as to solve the current problems of the city, region and country in an effective and innovative way.

As noted by Leshina M.A. in her article "On the question of the relevance of stimulating teachers of the Russian high school," "nowadays opportunities to attract young scientists and teachers in higher educational institutions are rather limited: on the one hand, they are limited by low salaries of university teachers who do not have academic degrees and titles as well as work experience in higher educational institution, on the other hand, these opportunities are limited by additional financial costs for a post-graduate education (the absence of the required number of budget-financed places in doctoral degree programs)» (Leshina, 2008). According to Hochberg L.M., Kitova G.A., Kuznetsova T.E., Shuvalova O.R., " the interest in learning, formed on the basis of conscious motivation, objectified by the need, represents the basic meaning for scientific activity. Motivation, interest and research need are all the necessary conditions for scientific research. The most important factor of the creative activity is its motivation as a set of driving forces that motivate a person to certain actions" (Hochberg, et al., 2010).

Motives for scientific activities are based on the diversity of interests and needs of an individual and show that the success of scientific work is mainly associated with meeting high-order needs. The "achievement motive" plays a decisive role among the motives of the scientific activity - the desire for success and goal achievement. The achievement motive is recognized by researchers as an underlying factor inherent in scientists and defined as the desire to meet the highest criteria and be successful in a competitive environment, as the desire to achieve goals most effectively. Developing the theory of achievement motivation, Heinz Hekhauzen emphasizes that "achievement motivation is aimed at a certain end result produced by own abilities of an individual - namely, it is aimed at success achievement or avoiding failure. Thus, achievement motivation is essentially focused on the target. It pushes a person to the "natural" result of a number of interrelated actions" (Hekhauzen, 2001). According to the definition of the scientist, achievement motivation is "an attempt to increase or maintain the highest possible abilities of a person to all activities, to which success criteria can be used, and where the implementation of such activities could lead to either success or failure" (Hekhauzen, 2001). According to Ilyin E.P. (2000), the desire to engage in scientific activities is due to the following reasons:

- desire for knowledge and creation of new and unknown (cognitive and creative needs) or the need for creative activity (Pieroni, 1970);

- desire to understand a given phenomenon and share the knowledge of its essence with the others;

- interest in a particular science or any particular issue;

- desire to be beneficial for all humanity, or at least solve some economic problems by means of one's own discovery;

desire to "place oneself on record" by the publication of one's own works;

desire to achieve a certain social status (to obtain degrees, titles);

desire for self-realization, glory, fame;

the possibility to hold a senior position, thanks to scientific activities, various material goods (Hekhauzen, 2001). Justifying theoretical positions of research we have made a number of operational definitions. We consider scientific potential of a young scientist to be an integrative professional and personal education that:

a) allows the scientist to purposefully develop him/herself in science;

b) helps creatively and independently (or in cooperation with other scientists) produce innovative ideas, develop innovative projects, create innovative products that meet the current needs of the society;

c) is represented in mobility, looking for alternative ways to solve problems, initiative in finding original approaches, research methods of the studied subject, means of financial support for one's own projects and the ways of their implementation on the market of relevant products.

The results of sociological monitoring conducted by researchers at the Russian universities, show that nowadays the leading motives for the work are financial incentives (stability and increase in remuneration). However, for university 
professors material gain is not an extra value for the sake of which they are engaged in professional activity (Safonova, 2009). Researchers Telegina I.P., Krakovetskaya I.V. (Telegina, 2010) distinguish the following leading motives for employment of university teachers:

- self-realization - the prestige of the profession, the image and prestige of the university, career opportunities;

- cognitive process, the search for truth, the interest in the chosen specialty, the desire to conduct research and development, creative nature and content of the work;

- social motives - the desire to transfer knowledge and experience to the younger generation, an interest in educational work, the desire to benefit society;

- financial incentives - wage growth, the ability to earn additional income;

- $\quad$ self-assertion and self-development - training opportunities, recognition in the form of academic degrees and titles, the possibility of the development of intellectual potential, belonging to the family dynasty;

- other motives include the convenient work schedule, long summer vacation, work in a public institution, favorable intellectual and cultural environment, and others.

The success of adaptation of young scientists to scientific and professional activities depends on satisfying their motives for research and cognitive activity.

\section{Survey Methodology}

In order to study the motivation of young scientists (under 30 years) we conducted sociological research in the form of the questionnaire survey. We used a target type of the sample - young scientists (master's degree students and doctoral students) of different universities in Almaty participated in the survey. The representativeness of a mass survey when using non-random types of the sample is provided among a sufficient number of respondents. The total number of selection consisted of 220 people; $48.5 \%$ of respondents - men and $51.5 \%$ - women. Taking into account the narrowness of such social group as young scientists, the mentioned total volume of the sample seems to be sufficient to provide representative data.

\section{Survey Results}

Leaving the socio-demographic characteristics of respondents without description, let's analyze the cluster of the stated problems. In the analysis of respondents' answers to the question about the future intentions of undergraduates, we revealed that the intention to engage in scientific activity is more common for women, while men are more focused on career growth. In general, a significant part of graduates (42.6\%) responded that they would work in accordance with a master's degree, but not in the university. The survey results on further intentions of doctoral students indicate that the intention to continue scientific activities is more common for men, not for women. Women often intend to combine teaching in universities and their scientific activities. However, some doctoral students are still in the search.

Overall, under the survey results the attitude of young university scientists to professional scientific and educational activities was determined by identifying priority causes and motives of their scientific activities. Thus, we received the following answers to the question "What is the purpose of your admission to the master's and doctoral department?"

Table 1 - Data on the purposes of admission to master's course, as far as gender and common data are concerned

\begin{tabular}{|c|c|c|c|}
\hline \multirow{2}{*}{ Answers } & \multicolumn{2}{|c|}{ Gender } & \multirow{2}{*}{ In total } \\
\hline & Male & Female & \\
\hline The completion of the master's program allows continuing scientific activities & $13.0 \%$ & $33.3 \%$ & $23.4 \%$ \\
\hline The completion of the master's program increases the chance for employment & $30.4 \%$ & $29.2 \%$ & $29.8 \%$ \\
\hline The master's degree gives an opportunity to realize one's personal potential in career & $47.8 \%$ & $16.7 \%$ & $31.9 \%$ \\
\hline The student is forced to enter a master's program, as there is no other place to work. & $3.6 \%$ & $11.6 \%$ & $9.2 \%$ \\
\hline $\begin{array}{l}\text { The completion of the master's program will allow becoming a teacher in the higher educational institution } \\
\text { (flexible working hours, the 56-day summer vacation) }\end{array}$ & $5.1 \%$ & $9.2 \%$ & $5.7 \%$ \\
\hline
\end{tabular}

The analysis of the responses shows that the majority of undergraduates consider self-realization as a leading motive. $3.9 \%$ of respondents consider career prospects as an important factor. Social reasons $(29.8 \%)$ takes the second place: after completion of the master's program it is easier to find a job and benefit society. The desire to engage in scientific activities takes the third place. $5.7 \%$ of respondents are passionate about further teaching in the university, they choose 
flexible working hours and the 56-day summer vacation as the main motive. For the rest of the respondents (9.2\%), admission to the master's degree program was a forced measure, as they stood "at the crossroads", had no job and took "time out" in such a way.

Due to low wages and shortage of human resources in higher educational institutions young scientists focus on combining academic or research positions with administrative posts, in the absence of significant professional experience it affects on the quality and results of their professional activities. The results of the survey on admission to doctoral studies show that the majority of doctoral students are focused on employment and successful career. Thus, $42.4 \%$ of respondents answered that PhD gives more chances in career, education, science, business, civil service, $36.4 \%$ of respondents answered that $\mathrm{PhD}$ improves the chance for employment in universities. The data show that the interest to engage in further research activities are increasingly common among women rather than among men. At the same time, men are showing great interest in working in higher educational institutions.

Motivational factors to work in the field of science reflect the situation at the macro level. Against the background of continuous reform of education and science, young scientists do not focus on achieving results in a chosen profession. Young scholars' opinion of overall prospects of national research is different from the point of view of natural scientists. In the survey, all respondents were asked to assess the state of the university research in Kazakhstan today. The respondents' answers are mixed: the answers "University science does not exist as a system" and "University science has developed very actively for the last years" were selected by the same number of respondents. The results of assessment of university research were analyzed according to the status of the respondent, taking into account the orientation of the educational program.

Table 2 - The assessment of university research (the results of answers are distributed depending on the status of the respondent, taking into account the scientific orientation of the educational program)

\begin{tabular}{|c|c|c|c|c|c|c|}
\hline \multirow[b]{2}{*}{ Answers } & \multicolumn{3}{|c|}{ Master's degree student } & \multicolumn{3}{|c|}{ PhD student } \\
\hline & $\begin{array}{l}\text { Social and } \\
\text { human } \\
\text { sciences }\end{array}$ & \begin{tabular}{|c|}
$\begin{array}{c}\text { atural and } \\
\text { engineering } \\
\text { sciences }\end{array}$ \\
\end{tabular} & In total & $\begin{array}{l}\text { Social and } \\
\text { human } \\
\text { sciences }\end{array}$ & $\begin{array}{c}\text { Natural and } \\
\text { engineering } \\
\text { sciences }\end{array}$ & \\
\hline University research is in an extremely poor condition. & 31.0 & 0.0 & 19.1 & 25.9 & 0 & 21.2 \\
\hline University research does not exist as a system. & 13.8 & 38.9 & 23.4 & 7.4 & 50 & 15.2 \\
\hline $\begin{array}{l}\text { There are some problems in the university research, but they are much } \\
\text { less than in other sectors (e.g. in research institutes). }\end{array}$ & 20.7 & 0.0 & 12.8 & 7.4 & 50 & 15.2 \\
\hline The university research has developed very actively for the last years. & 20.7 & 27.8 & 23.4 & 55.6 & 0 & 45.5 \\
\hline I find it difficult to answer as I am not aware ofthe situation. & 13.8 & 33,3 & 21.3 & 3.7 & 0 & 3.0 \\
\hline
\end{tabular}

Thus, a pessimistic view of the prospects for university research prevails among master's degree students of social and human sciences. The majority of master's degree students of natural and engineering sciences suppose that the university research does not exist as a system. Rather worrying figure (21.3\%) indicates an uncertain position of masters' degree students, not fully engaged in the research process. In the survey all participants from among doctoral students were asked to assess the state of university research in Kazakhstan today. A significant part of doctoral students (45.5\%) believe that university research has developed very actively for recent years. The analysis of the data shows that young scientists have the potential to be engaged in scientific activities, because they believe in the development of university research.

The trend of pessimism of master's degree students of social and human sciences can be traced in assessing the prospects and the level of motivation for scientific activity, evidenced by the results of the survey presented in Table 3. Thus, a significant part of the survey participants - master's degree students of social and human sciences believe that the overall situation will not improve. In general, it must be noted that master's degree students have a pessimistic opinion: $34 \%$ of students said that nothing would change, and $23.4 \%$ of respondents said that the overall situation would not improve. At the same time, data show that the proportion of those who said that the situation would not improve in priority areas, is higher among graduates of natural and engineering sciences. 
Table 3 - The assessment of the prospects and the level of motivation for research activities depending on the status of the respondent

\begin{tabular}{|l|c|c|}
\hline Answers & Master's degree student & PhD student \\
\hline There will be no improvement in some universities (national ones) & $12.8 \%$ & $24.2 \%$ \\
\hline Nothing will change & $34.0 \%$ & $12.1 \%$ \\
\hline The situation will improve in priority areas & $19.1 \%$ & $42.4 \%$ \\
\hline The overall situation will not improve & $23.4 \%$ & $45.5 \%$ \\
\hline Full recession of university research will happen & $10.6 \%$ & $15.2 \%$ \\
\hline
\end{tabular}

In addition to objective difficulties, young scientists face all sorts of barriers to complete participation in the research process. The largest share of master's degree students (27.7\%) consider the lack of language skills as a certain difficulty. It should be noted that the said problem is more common among graduates of social and human sciences. Besides, this category of respondents said that the lack of necessary skills to carry out scientific research is an obstacle to scientific activities. About a third of doctoral students (33.3\%) indicated the lack of funding for R \& D, while about a third (27.3\%) of respondents indicated the lack of language skills.

The professional strategies and attitudes of young scientists is affected by mismatch of significant components of their status, such as the level of education (training) and income. The consequences of the status mismatch in this group include the aggravation of social problems, such as low prestige of scientific sphere, an intensive outflow of young people from the scientific and higher education spheres, their labor migration to continue scientific career abroad, as well as downward professional mobility, social segregation, the growth of social apathy, which, in turn, increases the marginalization of the social status, etc. Low prestige of education and science among young people is the result of both the status mismatch and relatively high requirements for professional work in the conditions of reforming of higher education.

What are the conditions and factors that can help stimulate creative and innovative activities of young scientists?

Table 4 - Conditions and factors that can stimulate creative and innovative activities of young scientists, according to the opinion of PhD and master's degree students

\begin{tabular}{|c|c|c|}
\hline Answers & \multicolumn{2}{|c|}{ Master's degree studentPhD student } \\
\hline Conducting scientific competitions, conferences for young scientists & $8.5 \%$ & $3 \%$ \\
\hline State program to support talented young scientists & $14.9 \%$ & $27.3 \%$ \\
\hline Favorable conditions and stimulating scientific activity of Kazakhstan and foreign scientific funds & $25.5 \%$ & $27.3 \%$ \\
\hline The possibility of additional earnings & $19.1 \%$ & $12.1 \%$ \\
\hline The solution of social problems of young scientists (housing, support for young families, etc.) & $10.6 \%$ & $21.2 \%$ \\
\hline Enhancing the prestige of university research & $21.3 \%$ & $9.1 \%$ \\
\hline
\end{tabular}

The survey revealed that the first factor, stimulating creative and innovative activities of doctoral students, coincided with the first factor on the survey results among master's degree students: it is necessary to create favorable conditions and encourage scientific activity of Kazakh scientific foundations in every possible way. Next, we present two main different factors:

- Masters degree students suppose that it is necessary to improve the quality of higher education in Kazakhstan, as well as to create conditions for additional earnings.

- Doctoral students suppose that it is necessary to set up the state program to support talented young scientists and to solve social problems of young scientists (housing, support for young families, etc.).

\section{Discussion}

The youth is the priority and the main resource for the development of science. Building of the science capacity, the involvement of young scientists in the research process have become one of the key problems of the post-Soviet space. Qualifications of scientific advisors, the level and amount of research, links with research institutions are important criteria.

Kalinkin E.V. emphasizes that an important factor to enhance research work of the students is to improve the costeffectiveness of research activities of universities. The author considers the creation of teaching and scientific industrial 
complexes on the basis of university as one of the promising directions. This will allow enlarging the research, expanding the scope of research and speeding up the implementation process of completed works in the production. Creation of educational, scientific and industrial complexes will also allow conducting targeted research funding, using scientific equipment and material-technical base more efficiently, involving university staff into research (Kalinkin, 1982). In Kazakhstan, in particular, in the Al-Farabi Kazakh National University the conduct of students' competitions and innovative projects, as well as the establishment of students' business incubators was chosen as a way to stimulate the research.

In the indicative field Al-Farabi Kazakh National University takes into account the degree of participation of researchers and teachers in scientific research as a way to attract them to conduct scientific activities (on the basis of data of the indicative plan). The contests among universities are annually held for the best organization of students' scientific research in order to stimulate and improve the organization and management of students' scientific research.

For successful integration of Kazakhstan into the international education system it is necessary to take into account foreign experience of organizing and stimulating students' research activities. Ratner F.L., Petrov M.K. and several other authors studied the conditions of improving the students' scientific work in foreign countries. The researchers note that abroad since the 60-s of the twentieth century the so-called research training has been introduced when a talented student does not work over the graduation project, but he/she writes a thesis from the beginning of his/her studies in the university. Students are taught in the separate team, under the individual plan, the selection of such students for the program is carried out very strictly. This form of training is characterized by very close relations with the scientific management and of high performance. Particular emphasis is placed on consultation as a method for controlling student's research activities, the practice, student design bureau (SDB) and links with production institutions play a great role in such training (Ratner, 1992; Petrov, 1992).

The article of Georgieva T.S. examines the experience of US universities in cooperation with industrial enterprises. In recent years, the United States there is a trend towards greater involvement of private firms in the financing of university research, cooperation of universities with industrial enterprises has been steadily developing. Cooperation usually starts with the fact that firms use university scientists as consultants in conducting their own research. Then they conclude a contract on carrying out joint operations. In recent years, a number of design institutes is steadily increasing they represent research organizations independent of the university administration, and employ teachers, students and graduate students. Research and Science Parks represent another promising form of contact between universities and industrial enterprises in the conduct of scientific research (Georgiev, 1988).

The publication of Yurko N. discloses features of the system of higher education in Scotland. There are two graduate programs in this country. "Taught" program is similar to the Russian version, it includes lectures, seminars, passing midterm exams and tests. In contrast to the first program, "Research" program is designed for people conducting research, which are based on joint work with the academic adviser. The author notes that in recent years in the West using the distance learning programs has become very popular (Yurko, 2000).

The system of higher education and research activities in Germany has its own specificity. Frank E. and Opits Ch. in the article "Improving higher education in Germany," noted that the country has actively discussed the problem of increasing the competitiveness of the university system. Politicians agree that by reforming higher education in Germany a system of training of highly qualified specialists should be created. This system can operate effectively in a competitive environment.

The authors of the article propose to radically change the structure of the education market in Germany. Formation of a hierarchy of universities make them more involved in "reputation management" in order to attract the most talented students and have the opportunity to conduct research at a high level (Frank, \& Opitz, 2002).

Kazakhstan researcher G.S. Abdiraiymova assesses in her studies the level of development of science in Kazakhstan (Abdiraiymova, 2012, p. 58). Nowadays the young scholars' opinion of the development level of science in Kazakhstan allows saying that their attitude to the problem is negative. We can say that there is no one-sided assessment in the social opinion of youth. The majority of respondents (27.5\%) answered that "Science in Kazakhstan is of the average level by CIS (Commonwealth of Independent States) standards". Respondents are of the high opinion concerning the level of scientific personnel, first of all speaking of their experience and qualifications (6.1 points). Information support is on the third place with 5.8 points. Scientists' salary has the lowest grade of 4.3 points. On the last positions of rating there are also such items as "Implantation of scientific achievements into practice" and "Material and technical support of research institutions". Other indicators were rated between 5.5 and 5.2 points.

The "young scientists" groups were founded in the Soviet Union at the Institute of Science, in the 60-s of the twentieth century, their scientific achievements were recognized by the world at that time, thus science has been strictly controlled by the Soviet authorities (Abdiraiymova, et al., 2014). During this period, the first conferences for young 
scientists were held, as a result the Council of young scientists and experts was founded. After the Soviet period the attention of society and government to the scientists in this field increased in the 90-s of the twentieth century, at that time science in the country was experiencing difficulties because of changes in the Kazakh society, as a result, scientific research has fallen in bad condition, because the consumer sector of the economy was not available and it was impossible for scientists to go abroad. The introduction of the "young scientist" concept to scientific environment during this period showed to foreign countries the socio-political situation in Kazakhstan in the XX-XXI centuries and characterized as a historical period: science faces a lot of problems during the period of crisis and destruction, but at the same time, it could help the country to overcome the difficulties of this period. Scientific research plays a very important role in the creation of the source of the economic growth in the traditional system.

In the field of employment support of scientific and innovational activities directed to help employees in higher education and science, the government uses separate measures in order to correct the backward phenomena and difficulties of the last twenty years. However, they were isolated and were aimed at individual groups of scientists and experts, so did not lead to any major changes in the country's scientific and technical complex. Development and implementation of measures to support young scientists took place for the first time in national major projects and research programs.

As in western countries, "young scientist" category in Kazakhstan includes young people who are involved in science, research and pedagogy, academic activities at the universities and research institutions (Zhanazarova, 2013). They have higher education or post-graduate education degree directed at professional self-development in the field of education and science, they are characterized by constant development of their knowledge and improvement of their skills. According to their way of living, young scientists belong to the middle class, but having the necessary cultural education, natural resources, most of them do not have economical and social resources, therefore, in order to achieve this level they do it with the help of extensive professional activities or collected family funds.

Due to outstanding achievements reached over the past few years, the growing trend in Europe becomes more optimistic for science development, and got in accordance with European Union values and aspirations of their citizens (Mutanov et al, 2013). In this regard better opportunities are provided not only for a deeper establishment of relations with other European countries, but for better development possibilities. In this way, by common opinion, we are witnessing the need for a close relationship with constantly growing Europe in political and academic world, we understand that building and strengthening of intellectual, cultural, social and scientific-technological capacity is growing day after day.

\section{Conclusion}

The transformation processes taking place in Kazakhstan during the last 20 years, have influenced the value of the structure and system of values of young people, their professional plans and preferences, as well as in different social and professional groups. Achieving material wealth (29.8\%), career (41.1), the availability of interesting work (29.1) became indicators of success in life of young people. However, in the structure of motivation for choosing scientific career such factors as an interest in science, the creative work, the opportunity to realize one's own intellectual potential are the predominant ones, i.e. motives that attract young people to science and are not traditionally associated with income acquisition. Research and academic activities are regarded as a powerful resource for self-development, the most of young people consider the scientific activities as the only opportunity for professional self-realization. This demonstrates that such choice is made not by accident, scientific career is a conscious choice and it is conditioned by striving for creative, intellectual activity. The survey revealed the sustainable socio-psychological behavior model of young scientists and conservation of practices, traditional for research and academic areas as the possibility of exercising specific roles (as a researcher or a teacher).

However, against pessimistic assessments of the prospects for the formation of sustainable motivation of young scientists working in universities, for research activities it is necessary to create certain conditions, including: raising the prestige of university research; encouraging young people to participate in research activities; attracting young teachers and researchers to participate in solving creative scientific problems using modern innovative methods; youth involvement in scientific projects and developments aimed at solving urgent problems in various fields of science of a high priority both for the university and the state as a whole.

The sociological study revealed that a social factor may play an important role in the formation of motivation for obtaining higher education and employment in research activities. On the basis of the analysis of the scientific literature on the problems of research activities development, and the results of applied social study we can make the following recommendations.

The main motives for participation in R\&D are the motives for self-realization and raising self-esteem. Incentive 
measures should take into account the specific needs and interests of young scientists. Thus, financial incentives are not dominant for this category of young people, they mostly strive for the recognition of the social significance of their scientific activity, the demand for results of this activity. The system of incentives for young scientists should be based on the development of a set of measures of social protection (guarantees of employment, the development of a special system of housing and utilities, health care, information benefits), enabling a targeted and in-depth engage in research activities. The leading motive of young scientists is the motive of the status acquisition (obtaining higher education (diploma), the desire to find a high-paying job, take a worthy position in society), and their attitude to R \& D is more of an instrumental than terminal character.

The analysis of the results of the research project allows mapping out the further direction of research. We recommend to pay attention to the study of organizational, informational and staffing support of scientific activities, communicative aspects of research, issues on providing young scientists with benefits of a different nature, the correlation of university research with the production sphere, the degree of realization of the rights and freedoms of young scientists involved in research, the system of incentives for all research participants. It is necessary to expand the sample of sociological studies (to include young scientists from other universities, other regions in the sample), conducting surveys among teachers, expert interviews with different categories of research participants, as well as using extensive comparative material: data on national and regional statistics, regulatory and legal documents of other regions of the country (Almaty, Astana, Karaganda, Shymkent, etc.).

\section{References}

Science: Difficult frontier of the struggle for survival. (n.d.). Retrieved June 6, 2015, from http://www.kzpg.ru.

Leshina, M. (2008). The issue on relevance of stimulating teachers of the Russian Higher School. Personnel Management, 21, 23-25.

Hochberg, L., Kitova, G., Kuznetsova, T., \& Shuvalova, O. (2010). The Russian scientists: the finishing touches to a sociological portrait (pp. 5-6). Moscow: State University - Higher School of Economics.

Hekhauzen, H. (2001). Psychology of achievement motivation (pp. 17-23). Saint-Petersburg: Piter.

Ilyin, E. (2000). Motivation and motives. Saint-Petersburg: Piter.

Safonova, O. (2009). Features of professional motivation of teachers of economic universities. Higher education in Russia, 9, 152-156.

Telegina, I. (2010). Approaches to assessing the motivation of professional work of employees of high school on the basis of innovation. Bulletin of Tomsk State University, 3, 60.

Kalinkin, E. (1982). Scientific and technical potential of universities and the way of its effective use. Moscow.

Ratner, F. (1992). The scientific activity of students in Germany. Kazan.

Petrov, M. (1992). The socio-cultural foundations of development of modern science. Moscow.

Georgieva, T. (1988). The ways of development of cooperation of universities with the production (from the experience of USA high school). Bulletin of higher education, 4.

Yurko, N. (2000). Scotland: ancient clan, whose name - the youth. Elite education, 12; (2001). Sociology of Education, 9.

Frank, E., \& Opitz, Ch. (2002). Improving higher education in Germany. Sociology of Education, 1.

Abdiraiymova, G. (2012). Young scientists of Kazakhstan: rationale sociological portrait. Scientific publishing. Almaty: Kazakh University.

Abdiraiymova, G., Burkhanova, D., Serkizhanova, S., \& Verevkin, A. (2014). Scientific, educational strategies of young scientists as representatives of Kazakh middle class. Behavioral and Psychological Sciences, 116, 4880-4883.

Zhanazarova, Z. (2013). Innovative processes in education and science. Strategy of the Republic of Kazakhstan in the context of training innovative thinking specialists, 1, 31-33.

Mutanov, G., Burkitbayev, M., Ibrayeva, G., \& Abdiraiymova G. (2013). Kazakhstan in the European Higher Education Area (AHEA). Journal of the European Higher Education Area, 3, 67-91. 